\title{
Proinflammatory Soluble Interleukin-15 Receptor Alpha Is Increased in Rheumatoid Arthritis
}

\author{
Ana Cecilia Machado Diaz, ${ }^{1}$ Araceli Chico Capote, ${ }^{2}$ Celia Aurora Arrieta Aguero, ${ }^{1}$ \\ Yunier Rodríguez Alvarez, ${ }^{1}$ Diana García del Barco Herrera, ${ }^{1}$ Miguel Estévez del Toro, ${ }^{2}$ \\ Gerardo E. Guillen Nieto, ${ }^{1}$ and Alicia Santos Savio ${ }^{1}$ \\ ${ }^{1}$ Pharmaceutical Division, Center for Genetic Engineering and Biotechnology, 10600 Havana, Cuba \\ ${ }^{2}$ Rheumatology Department, H. Ameijeiras Hospital, San Lazaro 701, 10300 Havana, Cuba
}

Correspondence should be addressed to Alicia Santos Savio, alicia.santos@cigb.edu.cu

Received 20 February 2012; Revised 17 April 2012; Accepted 25 May 2012

Academic Editor: Adriana Rojas-Villarraga

Copyright (C) 2012 Ana Cecilia Machado Diaz et al. This is an open access article distributed under the Creative Commons Attribution License, which permits unrestricted use, distribution, and reproduction in any medium, provided the original work is properly cited.

\begin{abstract}
Rheumatoid arthritis (RA) is an autoimmune and inflammatory disease in which many cytokines have been implicated. In particular, IL-15 is a cytokine involved in the inflammatory processes and bone loss. The aim of this study was to investigate the existence in synovial fluid of soluble IL-15R $\alpha$, a private receptor subunit for IL-15 which may act as an enhancer of IL-15-induced proinflammatory cytokines. Soluble IL-15R $\alpha$ was quantified by a newly developed enzyme-linked immunosorbent assay (ELISA) in samples of synovial fluid from patients with RA and osteoarthritis (OA). The levels of IL-15R $\alpha$ were significantly increased in RA patients compared to OA patients. Also, we studied the presence of membrane-bound IL-15 in cells from synovial fluids, another element necessary to induce pro-inflammatory cytokines through reverse signaling. Interestingly, we found high levels of IL-6 related to high levels of IL-15R $\alpha$ in RA but not in OA. Thus, our results evidenced presence of IL-15R $\alpha$ in synovial fluids and suggested that its pro-inflammatory effect could be related to induction of IL-6.
\end{abstract}

\section{Introduction}

Rheumatoid arthritis (RA) is a chronic autoimmune disease in which imbalances in pro- and anti-inflammatory cytokines promote induction of autoimmunity, inflammation and joint destruction [1]. IL-15 is a proinflammatory cytokine associated with several autoimmune diseases, particularly rheumatoid arthritis. [2, 3]. Three different functional forms of IL-15 have been identified: the soluble cytokine [4], IL-15R-independent membrane-bound IL-15 $[5,6]$ and membrane-IL-15 anchored through IL-15R $\alpha$ [7]. IL- $15 R \alpha$ is a unique high affinity private $\alpha$ chain that together with the IL- 2 receptor, IL- $2 \mathrm{R} \beta$ chain and the IL-2R $\gamma$ chain subunits constitute a trimeric receptor for IL-15 on cell membranes. Also, IL-15R $\alpha$ may be secreted as a functional soluble molecule (s-IL-15R $\alpha$ ) and could behave as an agonist by forming a complex with IL-15 which is 100 -fold more efficient than the noncomplexed soluble cytokine or as an antagonist for IL-15 [8-10].
In addition, s-IL-15R $\alpha$ may activate a reverse signaling through interaction with IL-15R-independent membranebound IL-15, activating MAPKs (mitogen-activated protein kinases) and increasing production of several proinflammatory cytokines such as IL-6, IL-8, and tumor necrosis factor $\alpha$ $[5,6,11]$. This bidirectional signaling has also been described for most members of TNF ligand family contributing to multiple stages of immune regulation [12].

Soluble IL-15 has been detected in synovia of patients with RA mainly expressed by macrophages, fibroblasts, and endothelial cells $[13,14]$, and there it recruits circulating memory $\mathrm{T}$ cells in the synovial membrane and may up regulate TNF $\alpha$, IL-17, and other proinflammatory cytokines [15-17]. Moreover, soluble IL-15 appears to be an important contributor to osteoclastogenesis contributing to bone erosion [18-20]. Membrane IL-15 has been detected in synovial tissue of RA patients. However, the role of IL15R-independent membrane-bound IL-15 in RA has not been completely studied until now, and no data has been 
reported so far concerning the existence of natural sIL-15R $\alpha$ in synovial fluid of RA patients, two elements necessary to induce proinflammatory cytokines through reverse signaling that could contribute to pathogenesis of RA. Existence of different IL-15-activating signaling pathways for inducing inflammation in RA could imply use of different antagonists depending on the specific induced pathway(s).

We had previously identified P8 peptide as an IL-15R $\alpha$ antagonist that may be inhibiting reverse signaling [21]. Therefore, we focused our study on determining the presence of soluble IL-15R $\alpha$ in synovial fluid and its potential role in inducing reverse signaling through membrane-bound IL-15 on cells from synovial fluid. Interestingly, we found higher levels of IL- $15 \mathrm{R} \alpha$ in RA compared with OA, and also we found that there is a positive relationship between these high levels of IL-15R $\alpha$ and high levels of IL- 6 in RA but not in OA. Furthermore, we demonstrated in an in vitro experiment that IL-15R $\alpha$ induced secretion of IL- 6 in cells from synovial fluid of an RA patient. These results suggest the role of sIL-15R $\alpha$ as an inducer of the pro-inflammatory cytokine IL- 6 through a reverse signaling in RA.

\section{Subjects and Methods}

2.1. Patients and Samples. Synovial fluids were obtained from the knee joints of 35 patients. Eighteen (18) of them with established RA were receiving treatment with oral methotrexate (MTX) and low-dose prednisone. They were moderate or nonresponders to MTX with a mean DAS28 of 4.7 and had shown inflammation and abundant synovial fluid in the cavities of synovial joints. The rest (17) were OA patients. All patients were from the Rheumatology Service at Ameijeiras Brothers Hospital. Permission was obtained from the local ethics committee, and all patients gave written informed consent. Patient demographics are listed in Table 1.

Synovial fluid was directly aspirated from the inflamed joint and collected into tubes, immediately after we added hyaluronidase type IV (H3884, Sigma, USA) at $10 \mathrm{ug} / \mathrm{mL}$ to synovial fluid, and mixed by inversion followed by spinning at $1000 \mathrm{~g}$ for $10 \mathrm{~min}$ within $30 \mathrm{~min}$ of sample collection. The acellular portion of synovial fluid (synovial liquid) was stored at $-70^{\circ} \mathrm{C}$ before subsequent analysis. Cells were collected for flow cytometry and cell stimulation experiments.

2.2. Measurement of Serum $I L-15 R \alpha$. We have developed an enzyme-linked immunosorbent assay (ELISA) format to measure serum levels of IL-15R $\alpha$ as we have previously described [21]. The 96-well microtiter plates (Costar, Corning Inc., NY, USA) were treated with $2 \%$ glutaraldehyde solution for $2 \mathrm{~h}$ at $37^{\circ} \mathrm{C}$. After two washes with water, plates were coated with $10 \mu \mathrm{g} / \mathrm{mL}$ of $\mathrm{P} 8$ peptide/well, and the plates were then incubated at $4^{\circ} \mathrm{C}$ overnight. After three washes with phosphate buffered saline $\mathrm{pH} 7.4$ (PBS) containing $0.05 \%$ Tween 20, nonspecific binding sites were blocked by incubation for $1 \mathrm{~h}$ at $37^{\circ} \mathrm{C}$ in PBS containing $1 \%$ BSA. The blocking solution was replaced by samples (synovial liquid diluted 2-fold in PBS, containing 0.01\% BSA and
Table 1: Patient demographics.

\begin{tabular}{lcc}
\hline & RA $(n=18)$ & OA $(n=17)$ \\
\hline Sex $(\mathrm{M} / \mathrm{F})$ & $4 / 14$ & $9 / 8$ \\
Age (years) & $49 \pm 14.19$ & $64 \pm 9.8$ \\
Disease duration (years) & $13 \pm 11$ & $10 \pm 2.6$ \\
Rheumatoid factor $( \pm)$ & $6 / 12$ & - \\
DAS28 & $4.37 \pm 1.23$ & - \\
DMARD (MTX) & 16 & -
\end{tabular}

Demographics showing age, sex, and duration of disease, where available; RF: rheumatoid factor status; DAS28: disease activity score; DMARD: disease-modifying antirheumatic drug.

$0.05 \%$ Tween 20 or different concentration of recombinant IL-15R $\alpha$-Fc (147-IR, R\&D) in the same buffer). All the samples were in triplicate. Following incubation at $37^{\circ} \mathrm{C}$ for $2 \mathrm{~h}$, we did three washes with PBS containing $0.05 \%$ Tween 20. IL-15R $\alpha$ was detected with specific antibody against IL-15R $\alpha$ (AF247, R\&D System). The bound IL$15 \mathrm{R} \alpha$ was detected with HRP-conjugated goat antihuman IgG (A0170, Sigma, USA) by incubation at $37^{\circ} \mathrm{C}$ for $1 \mathrm{~h}$, followed by 5 washes with PBS, $0.1 \%$ Tween 20 . The reaction was visualized by adding the substrate solution $\left(3,3^{\prime}, 5,5^{\prime}\right.$ tetramethylbenzidine $[\mathrm{TMB}])$, and absorbance at $450 \mathrm{~nm}$ was measured with an ELISA plate reader (Biotrak GE, Healthcare, USA). The detection limit was $0.25 \mathrm{nM}$.

2.3. Immunoassays for IL-6. Interleukin-6 concentrations were measured in duplicate using commercially available ELISA kits purchased from R\&D Systems (Quantikine Human IL-6, D6050). The detection limit was $3.12 \mathrm{pg} / \mathrm{mL}$.

2.4. Western Blot Analysis. We precipitated IL-15R $\alpha$ from the synovial fluid with cold acetone. Proteins were separated on $12.5 \%$ SDS-PAGE and transferred to nitrocellulose membranes. Membranes were blocked in 5\% nonfat dry milk in Tris-buffered saline (TBS) ( $\mathrm{pH} 8$ ) for 1 hour at room temperature before probing for $2 \mathrm{~h}$ with antibody against IL$15 \mathrm{R} \alpha(0.5 \mu \mathrm{g} / \mathrm{mL})$ (AF247, R\&D System). After incubation with horseradish-peroxidase- (HRP-) conjugated secondary antibodies (rabbit anti-goat HRP, 1 : 1,000 dilution) (A8919, Sigma, USA) in $5 \%$ in TBS ( $\mathrm{pH} 8)$ for $1 \mathrm{~h}$ at room temperature, bound antibodies were visualized using enhanced chemiluminescence (Amersham Pharmacia Biotech, Little Chalfont, UK).

2.5. Flow Cytometry. Freshly isolated cells collected by centrifugation from synovial fluid were washed with PBS, 2\% fetal calf serum (FCS), and incubated on ice for $1 \mathrm{~h}$ with an anti-IL-15 mAb (MAB2471; R\&D System), or an irrelevant IgG1 isotype control mAb (MAB002; R\&D System), antiCD3 (sc1239; Santa Cruz Biotechnology), or anti-CD8 (sc 7970; Santa Cruz Biotechnology). Cells were then washed and incubated on ice for 30 minutes with anti-mouseFITC (F2772, Sigma, USA). After washing once with PBS $2 \%$ FCS and once with PBS, cells were resuspended in $1 \%$ 
paraformaldehyde and analyzed in a PAS-III flow cytometer using FloMax software (Partec, Germany).

For acid treatment, cells were incubated in ice-cold glycine buffer ( $25 \mathrm{mM}$ glycine and $150 \mathrm{mM} \mathrm{NaCl}[\mathrm{pH} 3.0]$ ) for 10 min previously incubated with specific antibodies.

2.6. Cell Stimulation with IL-15R $\alpha$. Cells were incubated in 24-well plates at $10^{6}$ cells per well either with or without sIL-15R $\alpha$ at $250 \mathrm{ng} / \mathrm{mL}$ as duplicates in two independent experiments. After 72-hour incubation, supernatants were collected and stored at $-70^{\circ} \mathrm{C}$ until further evaluation. IL6 concentration was determined by ELISA (D6050, R\&D Systems, Minneapolis, MN, USA).

2.7. Statistics. The nonparametric Mann-Whitney $U$ test was used for group comparisons of IL-6 and IL-15R alpha serum levels. The correlation coefficient was obtained by the nonparametric Spearman's rank correlation test.

\section{Results}

3.1. Increased SIL-15R $\alpha$ Levels in Synovial Fluid from Patients with RA. An indirect ELISA assay was performed to measure IL-15R $\alpha$ concentration using P8 peptide as capture. Therefore, we detected IL-15R $\alpha$ using an anti-IL-15R $\alpha$ antibody (AF247, R\&D) as a detection antibody as previously described [21]. Human sIL-15R $\alpha$-Fc fusion protein (R\&D) was used as standard with a detection limit of $0.25 \mathrm{nM}$. Next, we measured the IL-15R $\alpha$ level in synovial fluid from patients with RA or OA. The sIL-15R $\alpha$ was detected in 18 of 18 RA patients $(100 \%)$ versus 14 of 17 patients of OA $(82.3 \%)$. A significant increase in concentrations of sIL-15R $\alpha$ was observed in synovial fluid collected from RA patients compared to those from OA patients (Figure 1).

To confirm IL-15R $\alpha$ protein in synovial fluids, we used P8 peptide synthesized on TentaGel-S pearls to capture IL-15R $\alpha$. Proteins bound to TentaGel-P8 peptide were eluted and analyzed by immunoblotting assay using a specific anti-IL$15 \mathrm{R} \alpha$ antibody (AF247, R\&D). A band was detected between 29 and $66 \mathrm{kDa}$ (Figure 2), corresponding to previously described size around $55 \mathrm{kDa}$ [9].

3.2. Synovial Cells Express Membrane IL-15. To study the presence of membrane-bound IL-15, we analyzed the expression of membrane IL-15 by FACS in cells present in the synovial fluid. As shown in Figure 3(a), there is a different cell population in synovial fluids, but we only detected the expression of membrane IL-15 in R1 region (Figure 3(b)). The mIL-15 detected varied among patients, and interestingly, we found that the cell population in R1 region also expresses CD3 (Figure 3(c)) and CD8 markers (Figure 3(d)).

In addition, we tested whether IL-15 was expressed as membrane-IL-15 anchored through IL-15R $\alpha$ or as IL-15Rindependent membrane-bound IL-15. To accomplish this, we performed acidic treatment to remove membrane-IL-15 anchored through IL-15R $\alpha$ as reported by Dubois et al. [7]. This result showed a slight decrease in the amount of cellsurface-bound IL15 after acidic treatment which suggests

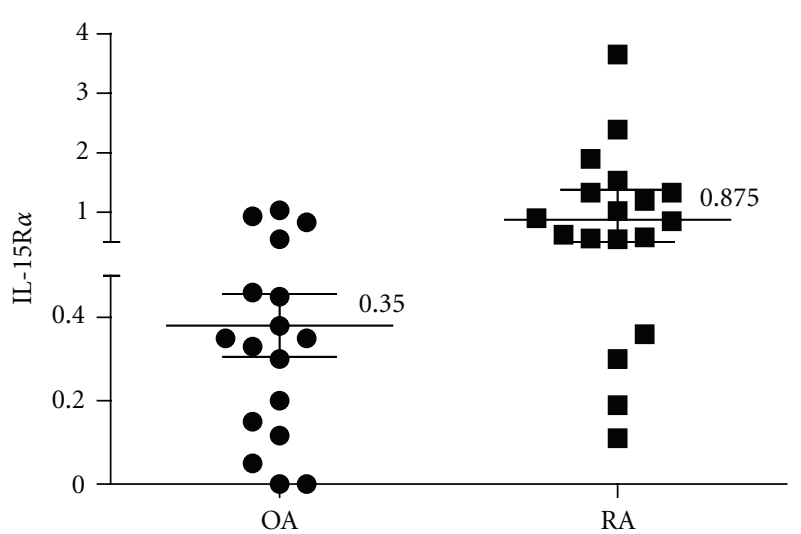

Figure 1: Increased sIL-15R $\alpha$ levels in RA synovial fluids. The graphic represents median and interquartile range. Mann-Whitney test shows a significant difference, $P=0.0025$, between OA and RA groups.

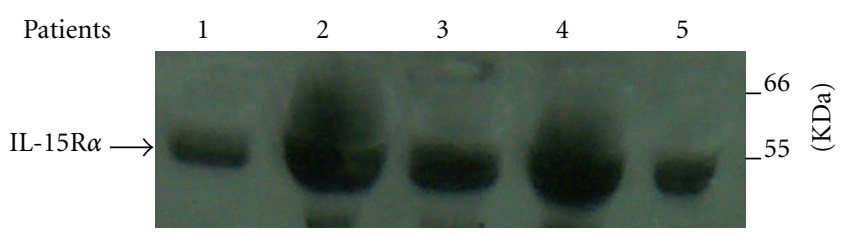

FIGURE 2: Western blot analysis of IL-15R $\alpha$ in synovial fluids from RA patients. Proteins from synovial fluids from different patients (lanes 1-5) were separated on $12.5 \%$ SDS-PAGE and transfer to nitrocellulose for western blotting. The western blot was probed with anti-IL-15R $\alpha$ antibody and development with anti-goat-HRP. Representative western blot is shown.

that part of the protein could be associated to IL-15R $\alpha$ in the membrane, but most of IL-15 is expressed as a membraneanchored protein (Figure 3(e)).

3.3. Relationship between IL-6 and IL-15R $\alpha$ in Rheumatoid Arthritis. IL-6 levels were measured by ELISA in synovial fluids in both groups of patients, and we found that a high percent of RA patients (80\%) expressed high levels of IL$6(>700 \mathrm{pg} / \mathrm{mL})$ versus $35 \%$ of OA patients as shown in Figure 4. This result in our patients is in agreement with previous reports but interestingly, in RA but not in OA, synovial IL-6 levels were positively correlated with high levels of sIL-15Ra $(P=0.006)$. The result is showed in Figure 5.

In order to study the induction of IL- 6 by IL-15R $\alpha$ in cells from synovial fluid, we performed an experiment to incubate cells from synovial fluid of RA patient with IL-15R $\alpha$ and in Figure 6 show a strong activation of IL- 6 secretion determined by ELISA after $72 \mathrm{~h}$ of treatment.

\section{Discussion}

IL-15R $\alpha$ is a private receptor for IL-15 that plays an important role in the biology of this cytokine. It has been described as a membrane and soluble receptor in serum from mice and humans [9]. This recent study confirms the 


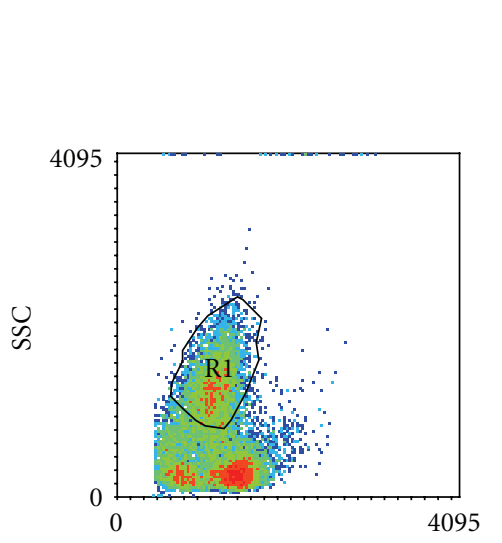

FSC

(a)

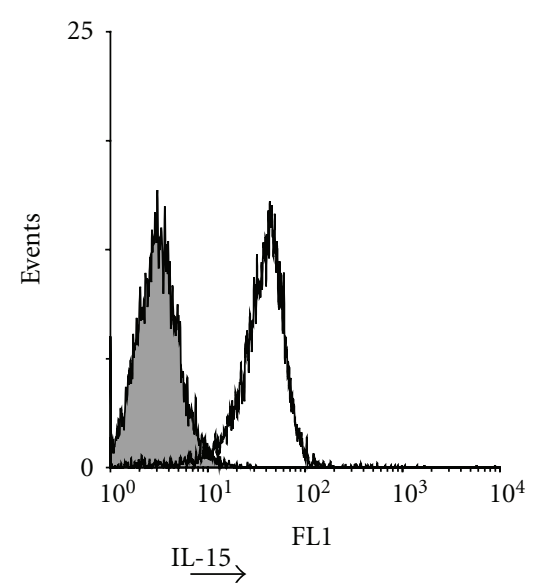

(b)

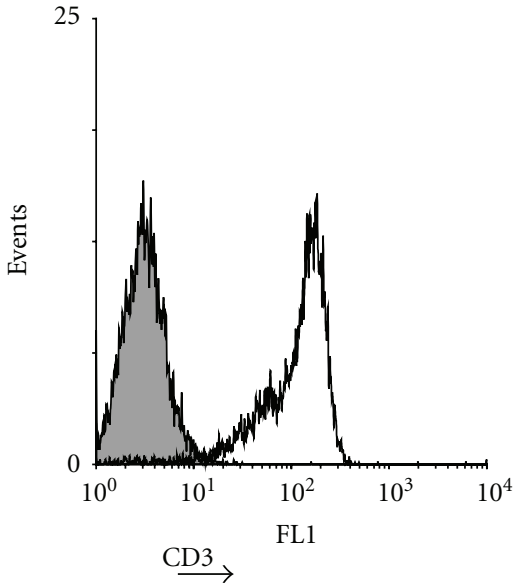

(c)

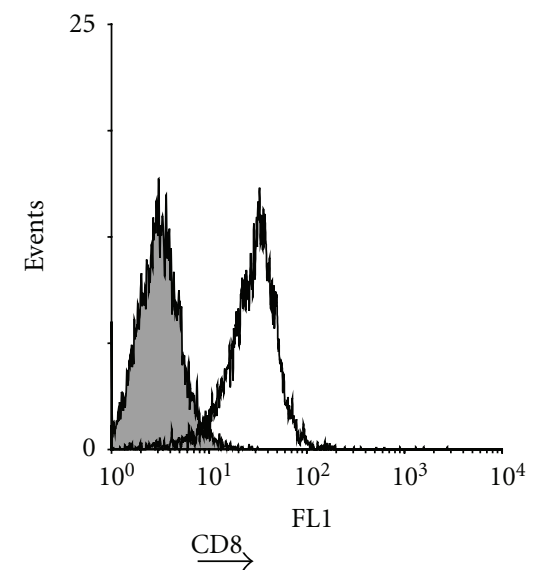

(d)

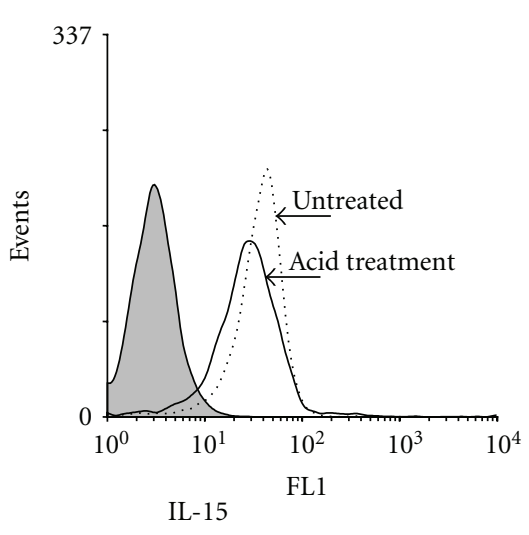

(e)

FIGURE 3: Flow cytometric analysis of a cell population positive for membrane-bound IL-15 (R1 region). Density plot had shown different population of cells in synovial fluid (a). Fluorescence intensity in R1 region is represented by white histograms, using a specific antibody MAB 2471(b); specific antibodies to detect CD3 (c) or CD8 (d) and gray histograms refer to the background staining. Acid treatment with acid buffer ( $\mathrm{pH}$ 3.0) before incubation with MAB 2471 produced a slight decrease in fluorescence intensity (bold gray line) in comparison to incubation with MAB 2471 in PBS (dotted line) (e).

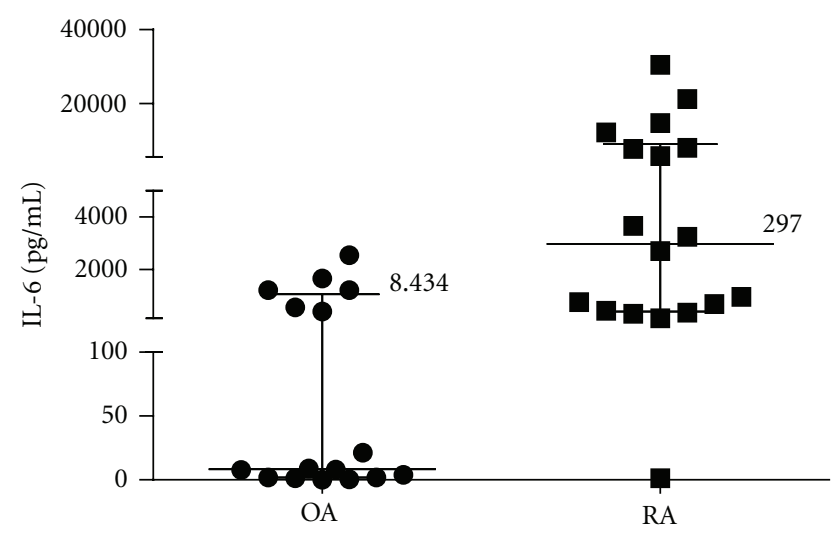

Figure 4: Increased IL-6 levels in RA synovial fluids. The graphic represents median and interquartile range. Mann-Whitney test has shown significant difference $P=0.0011$, between $\mathrm{OA}$ and $\mathrm{RA}$ groups. presence of soluble IL-15R $\alpha$ in synovial fluids from RA and OA patients, although it was undetected in 3 patients of OA. First, we established an ELISA using as a capture a previously described peptide which specifically binds to IL-15R $\alpha$ and displaces IL-15/IL-15R $\alpha$ binding in a dose-dependent manner [21]. Therefore, we considered that detected IL$15 \mathrm{R} \alpha$ is not forming complexes with endogenous IL-15. Measured levels of IL-15R $\alpha$ were significantly increased in RA compared with OA (a rheumatic nonautoimmune disease) suggesting a proinflammatory role in this disease. To determine the molecular weight of IL-15R $\alpha$ in synovial fluids, we captured it with a P8 peptide synthesized on TentaGel-S pearls. A band about $42 \mathrm{kDa}$ was recognized in a western blot using an anti-IL-15R $\alpha$ antibody. The observed size corresponded to the previous report for soluble IL$15 \mathrm{R} \alpha$ released from positive cells by a shedding process involving matrix metalloproteinases [9]. Presence of IL$15 \mathrm{R} \alpha$ in the synovial fluids is a requisite to induce reverse signaling through membrane-bound IL-15. A mechanism 


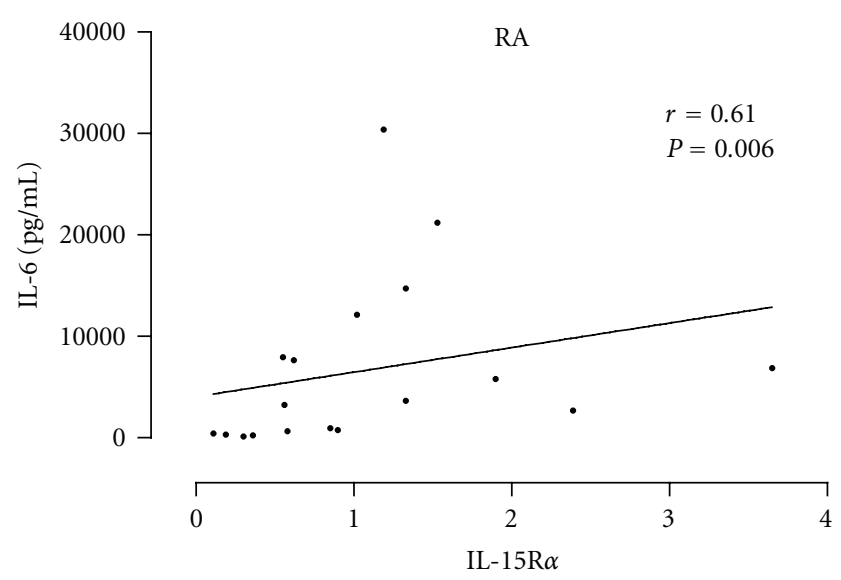

(a)

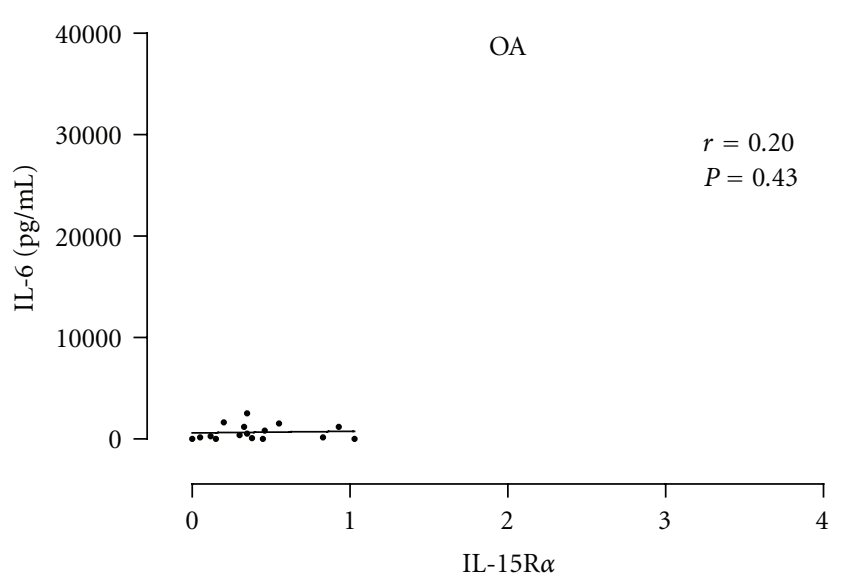

(b)

FIgURE 5: Correlation between IL-6 and sIL-15Ra levels in synovial fluid. Positive correlation was observed in RA $(r=0.61)$.

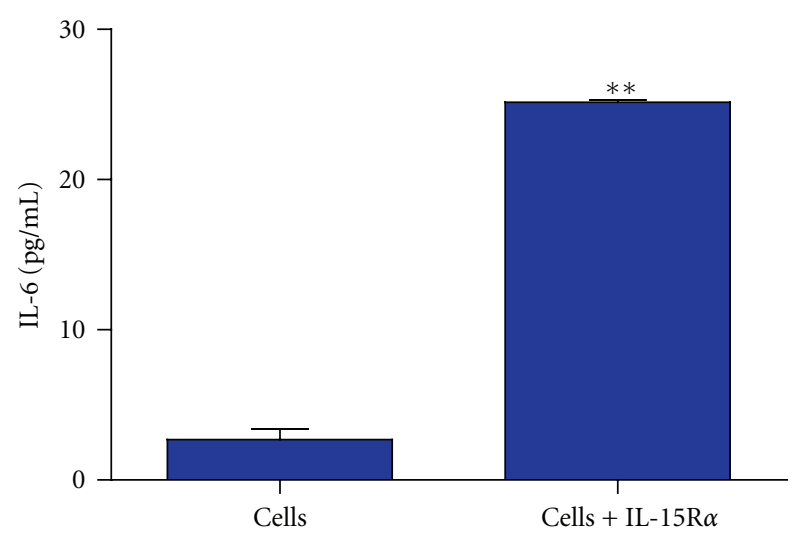

FIGURE 6: Effect of IL-15R $\alpha$ on IL-6 secretion in synovial cells. Treatment with $250 \mathrm{ng} / \mathrm{mL}$ of IL-15R $\alpha$ significantly upregulated IL-6 expression. Each bar represents the mean and SD of two determinations. $^{* *}=P<0.001$.

which has been recently described in THP1 monocytic cells, PC-3 prostate carcinoma cells and in patients with head and neck cancer. There it is proposed that IL-15 anchored in plasma membranes acts as a receptor being capable to bind soluble IL-15R alpha then inducing MAPK and IL-6. MAPKs (ERK and p38) are a family of highly conserved serine/threonine kinases that have been described to play key regulatory roles in downstream signaling events leading to joint inflammation, and joint destruction including production of proinflammatory cytokines such as IL-6 [22]. Expression of IL-6 is increased in the synovium of patients with RA, and serum levels of IL-6 have been shown to correlate with clinical and laboratory markers of disease activity, and IL- 6 has recently been validated as a target in RA [23]. Therefore, it is important to know if this signaling pathway induced by interaction between membrane IL-15 and IL-15R $\alpha$ takes place in RA to induce IL-6.

Although membrane IL-15 had been detected in synovial tissues from RA patients $[18,24]$, it has not been studied whether membrane IL-15 is bound to IL-15R $\alpha$ or exists as a membrane-anchored protein. In membrane IL-15 bound to IL-15R $\alpha$, IL-15 is retained on the cell surface, and it is transpresented to IL-2R/15R $\beta-\gamma c$ on nearby effector NK and $\mathrm{T}$ cells by the formation of an immunological synapse $[25,26]$. Thus, IL-15/IL- $15 \mathrm{R} \alpha$ activates the JAK1/JAK3 and STAT3/STAT5 pathways to induce proliferation of T and NK cells, and this mechanism could limit exposure to circulating IL-15, that contributeS to the risk of autoimmunity [7]. In contrast, IL-15 R-independent membrane-bound IL-15 could act as a receptor inducing reverse signaling. In this current study, we found that after acid treatment most of IL15 is present as a membrane-anchored protein, and a certain number of IL-15 molecules are bound to membrane IL-15 $\mathrm{R} \alpha$ confirming the expression of membrane-anchored IL-15 on cells from synovial fluids.

Chronic joint inflammation is related to leukocytes infiltration in synovial compartment. The synovium of patients with established RA is expanded and contains large numbers of fibroblasts, macrophages, and highly differentiated $\mathrm{T}$ cells [27]. We observed at least three cell populations with different SSC/FCS characteristics by flow cytometry (Figure 3(a)). We could not perform double staining, but interestingly, IL15 positive cells were present in the R1 region, and 95\% of this population was $\mathrm{CD} 3$ positive and $83.8 \%$ were CD8 positive, suggesting, they were IL-15-positive $\mathrm{T}$ cells. This finding is in agreement of previous results by Miranda-Carús et al., who detected IL-15 on rheumatoid arthritis T cells [18].

To explore the production of the proinflammatory cytokine IL-6 in these patients, we quantified IL-6 levels in synovial fluids from RA and OA patients. Higher and significant concentrations of IL-6 were found in RA when compared with OA patients. This result is in agreement with a previous paper [28], but interestingly, we found a positive correlation $(r=0.61 ; P=0.006)$ between high levels of IL-6 and high levels of IL-15R $\alpha$ in RA but not in OA. This data suggested that IL-15R $\alpha$ present in synovial fluids could be possibly inducing IL-6 through a reverse signaling pathway and then contributing to a proinflammatory medium in RA. 
To demonstrate that cells from synovial fluid could secrete IL-6 in response to IL-15R $\alpha$, we performed an experiment in which cells from synovial fluid were incubated with or without IL-15R $\alpha$. A significant increase of IL- 6 was observed in the supernatant culture of cells treatment with IL-15R $\alpha$.

This result reveals a possible proinflammatory role of soluble IL-15R $\alpha$ through reverse signaling. The presence of soluble IL-15 in synovial fluids from RA patients and its role in inducing migration of T cells and induction of TNF alpha is already known [8]. Possibly, both soluble and membrane IL-15 are implicated in the proinflammatory process through different pathways. Therefore, this finding might imply that different approaches would be necessary for an effective inhibition of IL-15 signaling in RA. Now, we will perform experiments to assess antagonist properties of the $\mathrm{P} 8$ peptide in this context.

In conclusion, we have detected soluble IL-15 alpha in synovial fluids, which is increased in RA in comparison to OA. In addition, it is positively correlated to IL-6 specifically in RA. These results suggested that IL-15R alpha could induce IL-6 in RA through its binding to membrane IL-15.

\section{Acknowledgment}

The authors thank Jenny Slattery for help in reviewing the paper.

\section{References}

[1] I. B. McInnes and G. Schett, "Cytokines in the pathogenesis of rheumatoid arthritis," Nature Reviews Immunology, vol. 7, no. 6, pp. 429-442, 2007.

[2] I. B. Mcinnes, J. Al-Mughales, M. Field et al., "The role of interleukin-15 in T-cell migration and activation in rheumatoid arthritis," Nature Medicine, vol. 2, no. 2, pp. 175-182, 1996.

[3] H. P. Carroll, V. Paunović, and M. Gadina, "Signalling, inflammation and arthritis: crossed signals: the role of interleukin-15 and -18 in autoimmunity," Rheumatology, vol. 47, no. 9, pp. 1269-1277, 2008.

[4] J. D. Burton, R. N. Bamford, C. Peters et al., "A lymphokine, provisionally designated interleukin $\mathrm{T}$ and produced by a human adult T-cell leukemia line, stimulates T-cell proliferation and the induction of lymphokine-activated killer cells," Proceedings of the National Academy of Sciences of the United States of America, vol. 91, no. 11, pp. 4935-4939, 1994.

[5] V. Budagian, E. Bulanova, Z. Orinska et al., "Reverse signaling through membrane-bound interleukin-15," The Journal of Biological Chemistry, vol. 279, no. 40, pp. 42192-42201, 2004.

[6] G. G. Neely, S. Epelman, L. L. Ma et al., "Monocyte surfacebound IL-15 can function as an activating receptor and participate in reverse signaling," Journal of Immunology, vol. 172, no. 7, pp. 4225-4234, 2004.

[7] S. Dubois, J. Mariner, T. A. Waldmann, and Y. Tagaya, "IL$15 \mathrm{R} \alpha$ recycles and presents IL-15 in trans to neighboring cells," Immunity, vol. 17, no. 5, pp. 537-547, 2002.

[8] E. Mortier, A. Quéméner, P. Vusio et al., "Soluble interleukin15 receptor $\alpha$ (IL-15R $\alpha$ )-sushi as a selective and potent agonist of IL-15 action through IL-15R $\beta / \gamma$ : hyperagonist IL- $15 \cdot$ IL$15 \mathrm{R} \alpha$ fusion proteins," The Journal of Biological Chemistry, vol. 281, no. 3, pp. 1612-1619, 2006.
[9] E. Mortier, J. Bernard, A. Plet, and Y. Jacques, "Natural, proteolytic release of a soluble form of human IL-15 receptor $\alpha$ chain that behaves as a specific, high affinity IL-15 antagonist," Journal of Immunology, vol. 173, no. 3, pp. 1681-1688, 2004.

[10] M. P. Rubinstein, M. Kovar, J. F. Purton et al., "Converting IL-15 to a superagonist by binding to soluble IL-15R $\alpha$," Proceedings of the National Academy of Sciences of the United States of America, vol. 103, no. 24, pp. 9166-9171, 2006.

[11] T. Thalhamer, M. A. McGrath, and M. M. Harnett, "MAPKs and their relevance to arthritis and inflammation," Rheumatology, vol. 47, no. 4, pp. 409-414, 2008.

[12] N. J. Chen, M. W. Huang, and S. L. Hsieh, "Enhanced secretion of IFN- $\gamma$ by activated Th1 cells occurs via reverse signaling through TNF-related activation-induced cytokine," Journal of Immunology, vol. 166, no. 1, pp. 270-276, 2001.

[13] I. B. McInnes, J. A. Gracie, M. Harnett, W. Harnett, and F. Y. Liew, "New strategies to control inflammatory synovitis: interleukin 15 and beyond," Annals of the Rheumatic Diseases, vol. 62 , no. 2 , pp. 51-54, 2003.

[14] N. Oppenheimer-Marks, R. I. Brezinschek, M. Mohamadzadeh, R. Vita, and P. E. Lipsky, "Interleukin 15 is produced by endothelial cells and increases the transendothelial migration of T cells in vitro and in the SCID mouse-human rheumatoid arthritis model in vivo," Journal of Clinical Investigation, vol. 101, no. 6, pp. 1261-1272, 1998.

[15] I. B. Mcinnes, B. P. Leung, R. D. Sturrock, M. Field, and F. Y. Liew, "Interleukin-15 mediates T cell-dependent regulation of tumor necrosis factor- $\alpha$ production in rheumatoid arthritis," Nature Medicine, vol. 3, no. 2, pp. 189-195, 1997.

[16] S. Ferretti, O. Bonneau, G. R. Dubois, C. E. Jones, and A. Trifilieff, "Il-17, produced by lymphocytes and neutrophils, is necessary for lipopolysaccharide-induced airway neutrophilia: IL-15 as a possible trigger," Journal of Immunology, vol. 170, no. 4, pp. 2106-2112, 2003.

[17] W. A. Verri, T. M. Cunha, S. H. Ferreira et al., "IL-15 mediates antigen-induced neutrophil migration by triggering IL-18 production," European Journal of Immunology, vol. 37, no. 12, pp. 3373-3380, 2007.

[18] M. E. Miranda-Carús, M. Benito-Miguel, A. Balsa et al., "Peripheral blood $\mathrm{T}$ lymphocytes from patients with early rheumatoid arthritis express RANKL and interleukin-15 on the cell surface and promote osteoclastogenesis in autologous monocytes," Arthritis and Rheumatism, vol. 54, no. 4, pp. 1151-1164, 2006.

[19] Y. Ogata, A. Kukita, T. Kukita et al., "A novel role of IL-15 in the development of osteoclasts: inability to replace its activity with IL-2," Journal of Immunology, vol. 162, no. 5, pp. 27542760, 1999.

[20] S. Djaafar, D. D. Pierroz, R. Chicheportiche, X. X. Zheng, S. L. Ferrari, and S. Ferrari-Lacraz, "Inhibition of T cell-dependent and RANKL-dependent osteoclastogenic processes associated with high levels of bone mass in interleukin-15 receptordeficient mice," Arthritis and Rheumatism, vol. 62, no. 11, pp. 3300-3310, 2010.

[21] A. Santos, A. Cabrales, O. Reyes et al., "Identification of an interleukin-15 antagonist peptide that binds to IL-15R $\alpha$," Biotecnología Aplicada, vol. 25, no. 4, pp. 320-324, 2008.

[22] T. Thalhamer, M. A. McGrath, and M. M. Harnett, "MAPKs and their relevance to arthritis and inflammation," Rheumatology, vol. 47, no. 4, pp. 409-414, 2008.

[23] P. Emery, E. Keystone, H. P. Tony et al., "IL-6 receptor inhibition with tocilizumab improves treatment outcomes in patients with rheumatoid arthritis refractory to anti-tumour necrosis factor biologicals: results from a 24 -week multicentre 
randomised placebo-controlled trial," Annals of the Rheumatic Diseases, vol. 67, no. 11, pp. 1516-1523, 2008.

[24] E. W. Thurkow, I. M. Van Der Heijden, F. C. Breedveld et al., "Increased expression of IL-15 in the synovium of patients with rheumatoid arthritis compared with patients with Yersinia-induced arthritis and osteoarthritis," Journal of Pathology, vol. 181, no. 4, pp. 444-450, 1997.

[25] T. Musso, L. Calosso, M. Zucca et al., "Human monocytes constitutively express membrane-bound, biologically active, and interferon- $\gamma$-upregulated interleukin-15," Blood, vol. 93, no. 10, pp. 3531-3539, 1999.

[26] H. Kobayashi, S. Dubois, N. Sato et al., "Role of trans-cellular IL-15 presentation in the activation of NK cell-mediated killing, which leads to enhanced tumor immunosurveillance," Blood, vol. 105, no. 2, pp. 721-727, 2005.

[27] N. J. Zvaifler, "The immunopathology of joint inflammation in rheumatoid arthritis," Advances in Immunology, vol. 16, pp. 265-336, 1973.

[28] T. Matsumoto, T. Tsurumoto, and H. Shindo, "Interleukin-6 levels in synovial fluids of patients with rheumatoid arthritis correlated with the infiltration of inflammatory cells in synovial membrane," Rheumatology International, vol. 26, no. 12, pp. 1096-1100, 2006. 


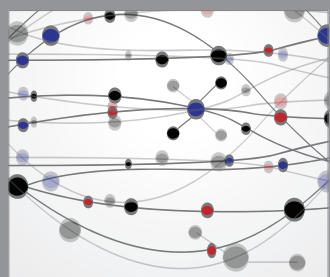

The Scientific World Journal
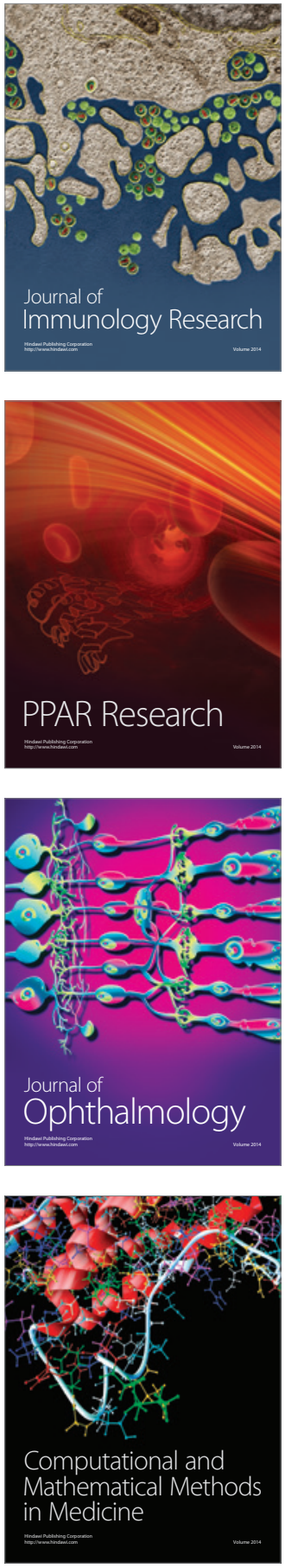

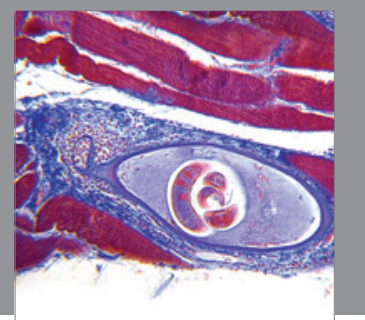

Gastroenterology

Research and Practice
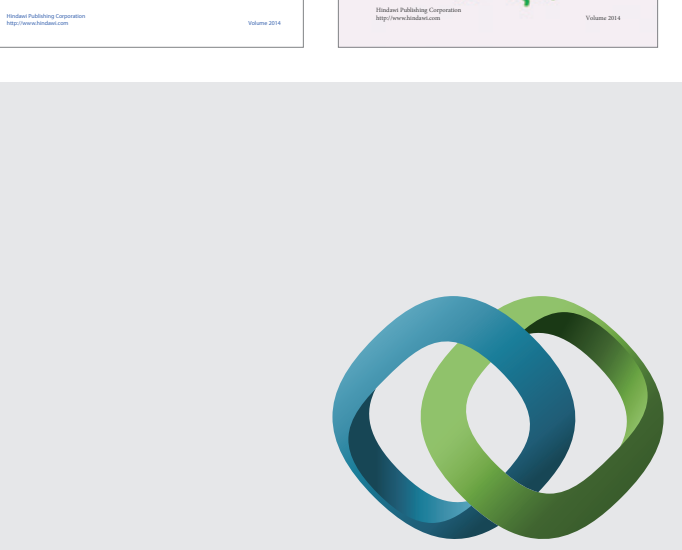

\section{Hindawi}

Submit your manuscripts at

http://www.hindawi.com
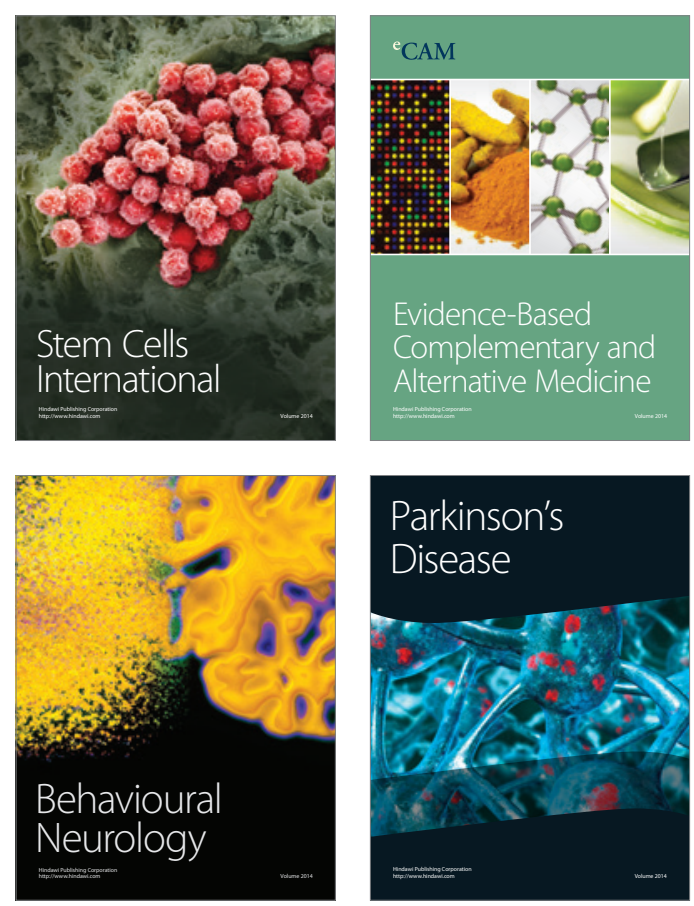

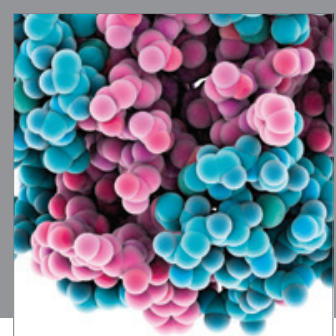

Journal of
Diabetes Research

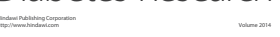

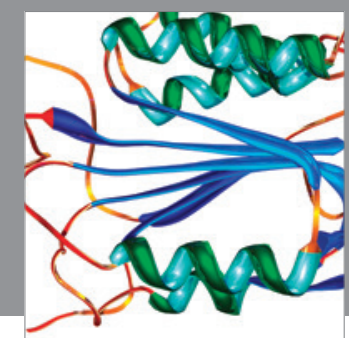

Disease Markers
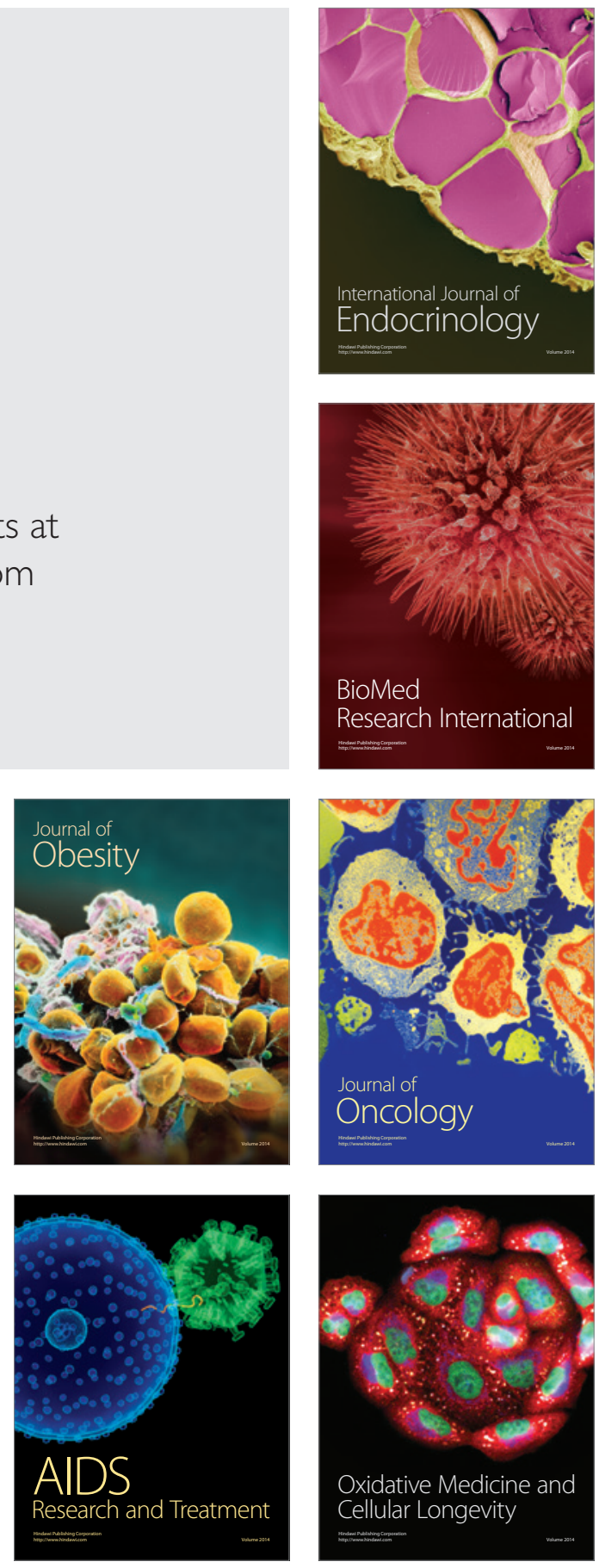